\title{
Structural Analysis of Nanocomposite Foundation for Marine Machinery
}

\author{
Chintada.vinod babu ${ }^{1}$ and Dr.K. Ramji ${ }^{2}$ \\ ${ }^{1,2}$ Department of Mechanical Engineering, GMRIT, Rajam, India. \\ ${ }^{2}$ Department of Mechanical Engineering, Andhra University, Visakhapatnam, India.
}

Received 18 May 2017; Accepted 8 September 2017

\begin{abstract}
This paper aims the development of a foundation structure for marine machinery use CNT reinforced with CFRP composite materials that would replace the existing structural material (mild steel). This paper thesaurus to show that the nanocomposite foundation structure provides better vibration control than the traditional material (like mild steel, brass) foundation and weight reduced from mild steel foundation to nanocomposite foundation. In the paper, all the structural analysis presented such as modal, static and frequency response analyses are done by using the finite element analysis package ANSYS. Natural frequencies are reduced 35-45 percent and weight reduced up to $40 \%$ by altering foundation material from mild steel to nanocomposite.
\end{abstract}

Keywords: Foundation for marine machinery, Nanocomposite, Vibration.

\section{Introduction}

The numerous features of composite materials have led to the widespread adoption in many different areas due to their unique features. Composite materials used in all mechanical and civil structures in load bearing applications due to their low cost, light weight and good environmental resistance. Low cost FRP composites are used in the process industry when the environment is highly aggressive and metal corrosion is a serious problem. FRP composites have low mechanical properties due to the polymer associated with it. Certain applications require improved mechanical behavior and some additional properties. So the nanocomposite materials are developed to meet the requirements. These composites are reinforced by nanoparticles.

All bodies possessing mass and elasticity are subjected to vibrations. Thus all engineering machines and structures experience vibrations. So the design generally requires consideration of their oscillatory behaviour. Vibration is a form of energy which is undesirable in many cases. For example in machinery, it generates noise, causes damage to the parts and transmits unwanted forces and moments to other bodies nearby.

Some times vibrations in structures and machine components lead to cyclic stresses resulting in material fatigue and failure. The transmission of vibrations to human beings results in discomfort. Sources of vibration in ships are mainly primary \& auxiliary machinery and propeller. These vibrations are transmitted to the hull through engine foundations and then as noise into surrounding water from the hull, which becomes a source of detection by other ships.

\footnotetext{
*E-mail address: vinodbabu.chintada@gmail.com ISSN: 1791-2377 @ 2017 Eastern Macedonia and Thrace Institute of Technology. All rights reserved. doi:10.25103/jestr.104.05
}

Hence the main objective is to reduce the structure born noise of the structure.

Conventionally, marine machinery foundations are made up of mild steel. Nanoparticle reinforced with FRP Composite materials is best alternative for certain characteristics including dynamic response, since the unique characteristic of composite material is its high internal damping. Composite structures combine materials which together result in a structure with properties not achievable with any of the constituents alone. Fiber-reinforced composites, specifically those based on ceramic and metal matrix material combine the best of both materials; inheriting the high stiffness and strength form the fibers while preserving the elevated temperature capabilities of the matrix material. In addition, the fiber-reinforced material tends to be more resistant to damage and defects that the homogeneous material. Their high strength to weight ratio allowed the design engineer to solve many stringent structural criteria in both space and military vehicles. Structures fabricated form composites improved craft mission capability through enhanced performance and increased payload capacity. The auxiliary advantage is that weight reduction, which translates into higher crushing speed, acceleration, maneuverability, and fuel efficiency.

\section{Literature Review}

Mouritz [11], scussed several of above discussed issues. Engine foundation material is changed to composite materials because of its lower weight; higher strength to machinery and equipment aligned with dynamic excitations is achieved by the composite foundation. The acoustic and magnetic signature of the ship is reduced by composite foundation due to non-magnetic and damping properties of 
the material. From this articles composite materials used as foundation material instead of mild steel.

Yankelevesky et.al [17] explains about the layered composite foundation analysis procedure it includes number of foundation layers. A algorithm and procedure is developed to calculate the Eigen values, characteristic roots and lengths, It was extended to find the effect of axial force in addition to transverse loading

Ching-Chieh Lin [5], attempt to describe Optimization and experiment of composite marine propellers. High strength to weigh ration and good corrosion of fiberreinforced plastic (FRP) are used in various structures. Bend-twist coupling effect is another unique characteristic of composite material. Most marine propellers are made of metal material such as bronze or steel is replaced with FRP composite materials because of its lighter weight, good corrosion resistance and controlled deformation of propeller results improvement in performance.

Kaplevatesky [8], attempted to illustrate layered composite element stress-strain state..To identifying elastic properties of laminates Rikards studied computational FE and experimental analyses. Walker and smith describe a procedure to optimal design of laminated fiber reinforced composite structure to maximum load carrying capacity.

Taylor and Nayfeh [16] develop a numerical calculations to simple supported thick composite layered plate for free vibrations. They investigate the microstructure and bonding agent effect on vibratory response of the plate by changing the natural frequencies. In this work by using computational methods natural frequencies of both the foundation is measured.

Gururaja M N, A N Hari Rao [6] revealed that Hybrid composite Materials have extensive engineering application where strength to weight ratio, low cost and ease of fabrication are required. Hybrid composites provide combination of properties such as impact strength, tensile modulus and compressive strength which are not obtained from composite materials. Hybrid composite are used when a linear and lateral mechanical performance and combined properties fibers required.

K.Ramji [2], attempt to describe a vibration analysis of carbon nanotube (CNT) reinforced layered composite materials. From this analysis it was conclude that addition CNT into glass fiber composite improves the natural frequency.

Horacio.V [7], revealed that Mechanical Properties of Nanocomposite Laminated Structures by Modal Method. The idea of this paper is to study the nanoparticle influence into the plate vibration behavior and to determine the elastic constants using the optimization procedure. To analyze only the nanoparticle influence all manufacturing parameters are kept fixed but the nanoparticle concentration. Modal analysis was done to determine the structural mode shape to compare the frequencies and modal properties for different nanoclay composite plates.

From the literature engine foundation material altered from traditional to nano composites (Mourtiz and Guru Raj).By using modal analysis (Taylor and Nayfeh) natural frequencies and mode shapes of the foundation is determined.

\section{Description of Finite Element Mode}

In ships, to support the machinery foundation is required. Here the foundation of a motor driven compressor is considered. In this foundation ten holes are presented to fix it to the ship hull. Motor driven compressor is fixed to the foundation by providing holes on the bed plates. Geometry of the foundation modeled in ANSYS software is shown in Fig-1. The elements SHELL 63 and SHELL 99 are considered to model metallic and nanocomposite foundations respectively.

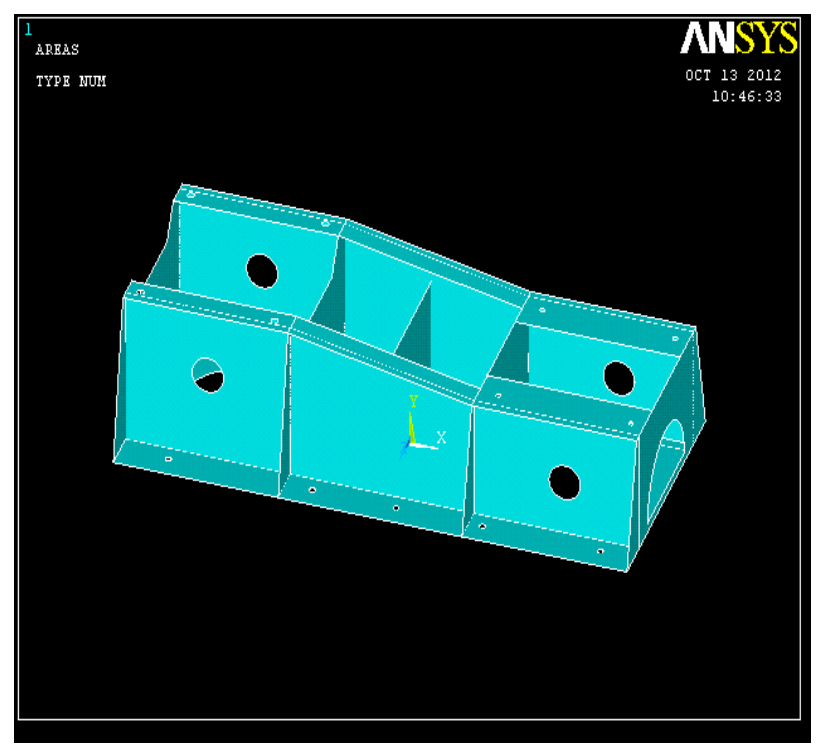

Fig. 1. Shell model of foundation

\subsection{Geometric Properties:}

The element types SHELL63 and SHELL99 require the thickness as the input. The foundation has various plates of different thicknesses. For both the foundations, the bed plates and base plates are of mild steel having thickness of 12 and $16 \mathrm{~mm}$ respectively. All other plates of mild steel foundation have a thickness of $6 \mathrm{~mm}$. For composite foundation other plate thickness is calculated with help of the following equation and is found to be $9.2 \mathrm{~mm}$ :

$$
T=\left(t_{\text {steel }}-C_{1}-C_{2}\right)\left(\frac{65000}{F_{u}}\right)^{n}(1.60)+k C_{2}
$$

Where,

$\mathrm{T}=$ minimum required $\mathrm{CNT}$ reinforced with CFRP thickness $t_{\text {steel }}=$ steel thickness

$C_{1} \quad=$ corrosion allowance for mild steel, for floors and girders $=1 / 16$ "

$C_{2} \quad=$ additional abrasion allowance, if any, for floors and girders $=0$

$\mathrm{k} \quad=$ wear rate of CNT reinforced with CFRP relative to steel

$\mathrm{F}_{\mathrm{u}} \quad=$ Tensile or compressive ultimate strength of CNT reinforced with CFRP

$\mathrm{n}$ is an exponent based on type of loading. For axial and shear loads, $\quad n=1$.For normal loads, $n=1 / 2$ and for a combination of axial and normal loading, a value of $3 / 4$ is recommended.

\subsection{Elements of Composite Foundation}

For the meshed composite foundation 'shell 99' element type is considered with 20 layers in a laminate. Each layer thickness is $0.45 \mathrm{~mm}$ and material reference numbers is ' 2 '. 


\section{Material Properties:}

Various properties of mild steel, and CNT reinforced with CFRP materials used for FE analysis are given in the following respectively.

Table 1. Material properties of mild steel

\begin{tabular}{c}
\hline MATERIAL NUMBER $=\mathbf{1}$ (STEEL) \\
\hline EX $=0.2 \mathrm{E}+12 \mathrm{~N} / \mathrm{m}^{2}$ \\
NUXY $=0.33$ \\
DENS $=7850.0 \mathrm{Kg} / \mathrm{m}^{3}$ \\
DAMP $=0.002$ \\
\hline
\end{tabular}

Table 2 Properties of CNT Reinforced with CFRP

\begin{tabular}{c|c}
\hline & CNT REINFORCED WITH CFRP \\
\hline EX & $7.07 \mathrm{GPa}$ \\
$\mathrm{EY}$ & $7.07 \mathrm{GPa}$ \\
$\mathrm{EZ}$ & $10.95 \mathrm{GPa}$ \\
$\mathrm{G}_{\mathrm{xy}}$ & $2.61 \mathrm{GPa}$ \\
$\mathrm{G}_{\mathrm{yz}}$ & $2.65 \mathrm{GPa}$ \\
$\mathrm{G}_{\mathrm{xz}}$ & $2.65 \mathrm{GPa}$ \\
NUXY & 0.34 \\
NUYZ & 0.35 \\
NUXZ & 0.35 \\
\hline
\end{tabular}

Where

EX, EY, EZ-Young's modulus; GXY,

GYZ, GXZ-Shear modulus

NUXY, NUYZ, NUXZ-Poisson's ratio;

DENS-Density; DAMP-Damping ratio

\section{Boundary Conditions:}

In general, the following types of boundary conditions are applied at appropriate locations of the foundation.

\section{Fixed condition:}

Fixed boundary conditions are applied to base plate hole nodes in this condition all DOF (degrees of freedom is under control, translations and all rotations (UX, UY, UZ, ROTX, ROTY and ROTZ) can be denoted by

$$
\mathrm{UX}=\mathrm{UY}=\mathrm{UZ}=\mathrm{ROTX}=\mathrm{ROTY}=\mathrm{ROTZ}=0
$$

Figure-2: shows the fixed boundary condition to the base plate holes of foundation.

\section{Simply supported condition:}

Simply supported condition is applied to the base plate holes in which, the translations along ' $\mathrm{Y}$ ' and ' $\mathrm{Z}$ ' directions are arrested, i.e. $U Y=U Z=0$. The rest translation along ' $X$ ' direction (UX) and rotations along all directions (ROTX, ROTY, ROTZ) are free. Similar boundary condition are used in bridges, beams etc.

\section{Free-Free condition:}

In this case base plate hole are free from the constraints that means all degrees of freedom is free. All translations and rotations are allowed. Natural frequencies of both the foundations are finding out by applying the free-free boundary conditions. Free-free boundary conditions of foundation shown in Fig-3

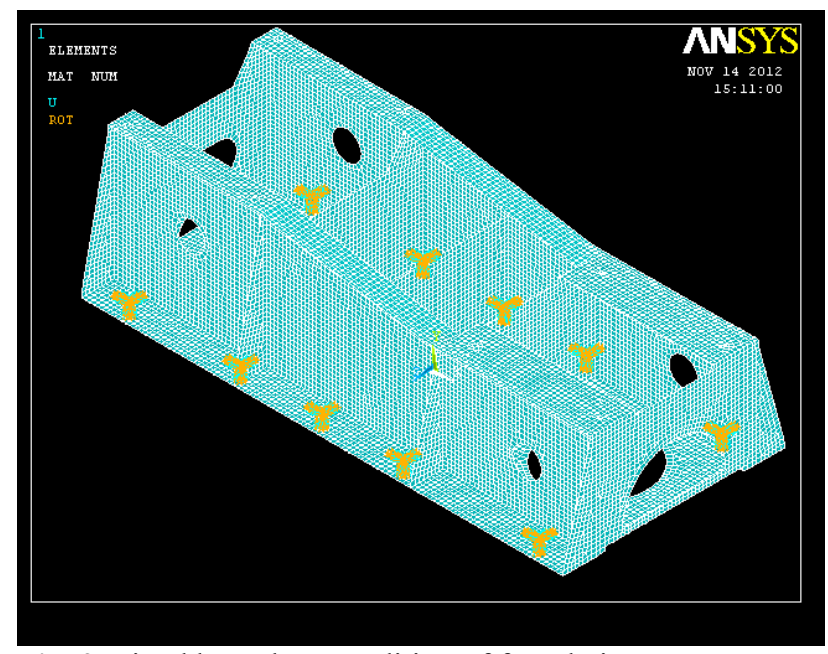

Fig. 2. Fixed boundary condition of foundation

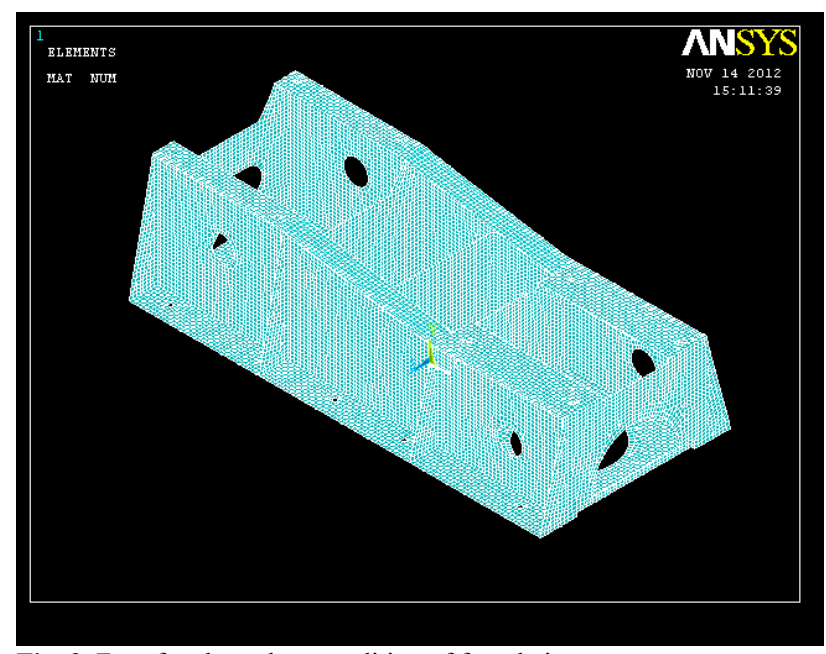

Fig. 3. Free-free boundary condition of foundation

\section{Elements Used:}

For FE analysis of mild steel foundation, element types SHELL 63 is selected and for the composite foundation (CNT reinforced with CFRP), the SHELL 63 element and SHELL 99 layered type element are selected. Shell 99 element is used to model thin to moderately thick plates of shell structures with side to thickness ratio around 10 , it is a 8 node 3D shell element with six degree of freedom at each node. This type of element allows up to 250 layers if more than 250 layers are required, a user-input constitutive matrix is available. The SHELL63 is a six nodded element, specifically suited to model curved shells. At each node element has six degrees of freedom, three translation and rotations about nodal $\mathrm{X}, \mathrm{Y}$ and $\mathrm{Z}$ directions. Element shell 99 has good plasticity, stress stiffening, and large deflection and strain capability

\section{Results and Discussion}

\section{Static analysis of Mild steel Foundation}

Static load (335 kg) of motor and compressor of an engine is applied on mild steel foundation. On base plate holes total load is equally distributed. Foundation is fixed on ship hull by using the base plate holes. Fixed boundary conditions applied to base plate holes to avoid the movement of the foundation at these locations. Magnitude of stresses is 
calculated from displacement, maximum displacement observed is $0.0047 \mathrm{~mm}$ for mild steel foundation. Von-Mises stress $18.7 \mathrm{Mpa}$ is obtained from this analysis shown in fig-4.

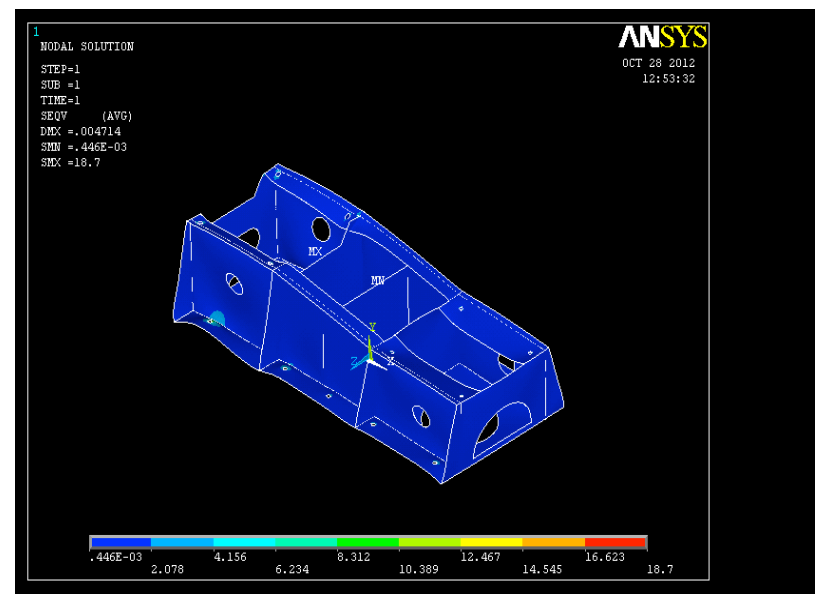

Fig, 4. Displacement and von-mises stress of mild steel foundation

\section{Eigen value analysis of mild steel foundation:}

Displacements, natural frequencies and mode shapes of the foundation are determined from eigen value analysis. Eigen value analysis fifteen modes are extracted in free-free condition, first natural frequency is observed at $7^{\text {th }}$ mode is $64.27 \mathrm{~Hz}$ due to free-free boundary condition. Structural behavior of the foundation at $7^{\text {th }}$ mode is shown in fig-5.The natural frequency at the last mode i.e. 15 th mode is 613.50 Hz. Table-3 shows mild steel foundation eigen value analysis in free-free boundary condition.

Table 3. Free-free Eigen value analysis results of mild steel foundation

\begin{tabular}{c|c}
\hline SET & FREQUENCY HZ \\
\hline 7 & 64.270 \\
8 & 354.07 \\
9 & 380.51 \\
10 & 399.06 \\
11 & 517.26 \\
12 & 553.87 \\
13 & 593.63 \\
14 & 599.98 \\
15 & 613.50 \\
\hline
\end{tabular}

Fixed boundary conditions is applied in constrained modal analysis on the base plate mounting holes, hear all degree of freedom is zero. Fifteen modes are extracted for this analysis, first natural frequency is observed at first mode, it is $351.67 \mathrm{~Hz}$ and at 15th mode it is $814.2 \mathrm{~Hz}$. The table-4 shows the constrained mild steel foundation eigenvalue results.

Table 4. Constrained eigenvalue analysis results of Mild steel foundation

\begin{tabular}{c|c}
\hline SET & FREQUENCY HZ \\
\hline 1 & 351.67 \\
2 & 380.05 \\
3 & 390.02 \\
4 & 509.70 \\
5 & 569.58 \\
6 & 588.50 \\
7 & 604.62
\end{tabular}

\begin{tabular}{c|c}
8 & 642.32 \\
9 & 683.73 \\
10 & 698.11 \\
11 & 714.58 \\
12 & 818.39 \\
13 & 830.23 \\
14 & 846.72 \\
15 & 849.47 \\
\hline
\end{tabular}

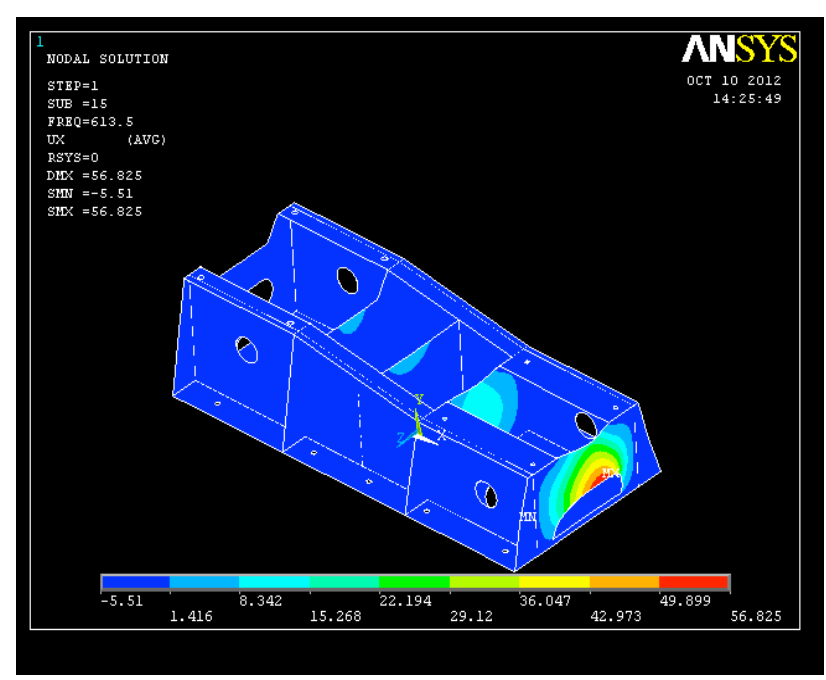

Fig 5. 15th mode shape of mild steel foundation (free -free boundary condition)

\section{Static analysis of Nanocomposite Foundation}

Static analysis of nanocomposite foundation was done by using the same procedure of the mild steel foundation. The static loads and boundary conditions were same as that of mild steel foundation. The total deformation is $0.8 \mathrm{E}^{-3} \mathrm{~mm}$ is observed in the composite foundation due to the static load is shown in the Figure-6

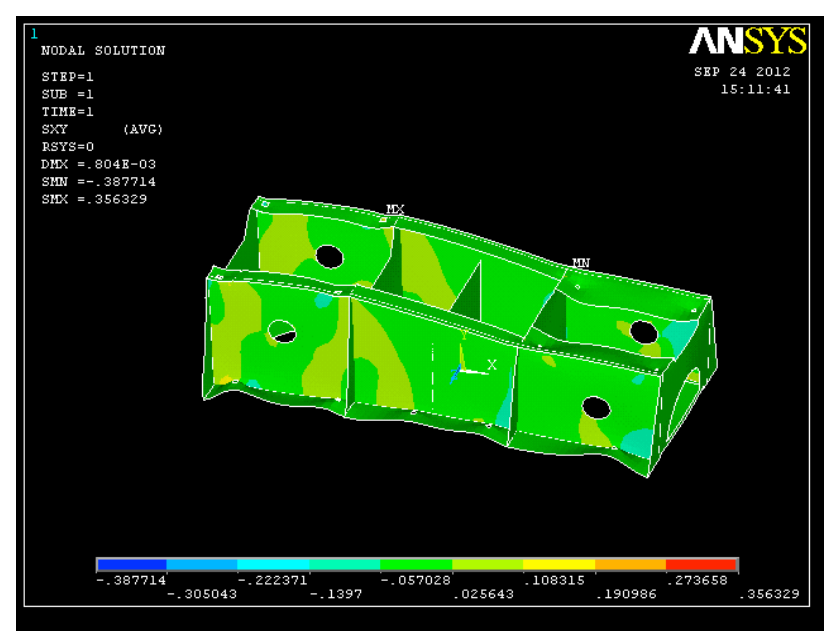

Fig. 6. Stresses in $\mathrm{X}$ directions (Sx) of composite foundation

The maximum stresses in ' $\mathrm{X}$ ' direction are $4.27 \mathrm{MPa}$, in ' $\mathrm{Y}$ ' direction is $1.897 \mathrm{MPa}$ and the shear stress along ' $\mathrm{XY}$ ' direction is $0.3566 \mathrm{MPa}$, which are safe.

Figure-7 shows stresses in $\mathrm{X}$ directions $\left(\mathrm{S}_{\mathrm{x}}\right)$ and Figure- 8 shows composite foundation $\mathrm{XY}$ direction shear stresses $\left(\mathrm{S}_{\mathrm{xy}}\right)$. 


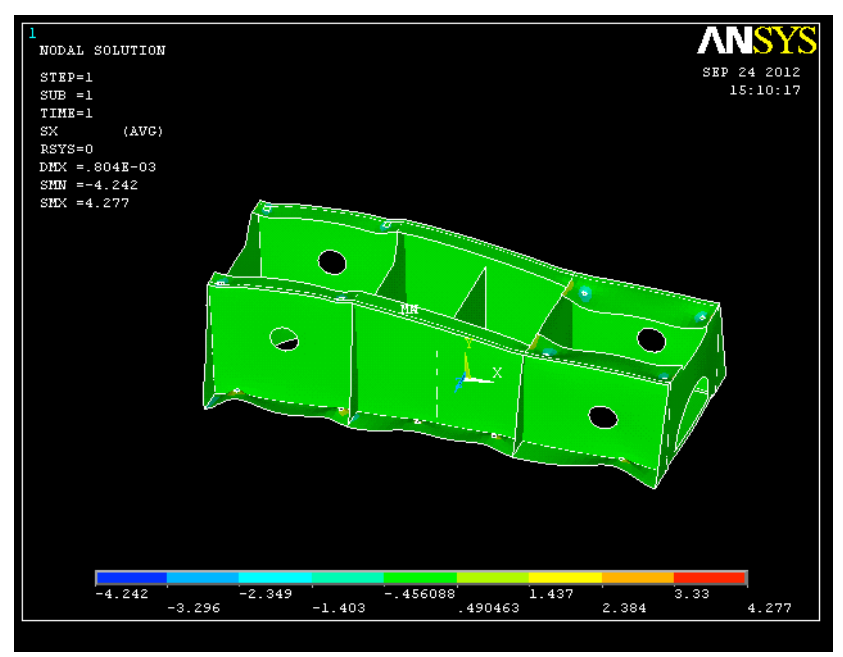

Fig. 7. Stresses in $\mathrm{Y}$ directions $\left(\mathrm{S}_{\mathrm{y}}\right)$ of composite foundation

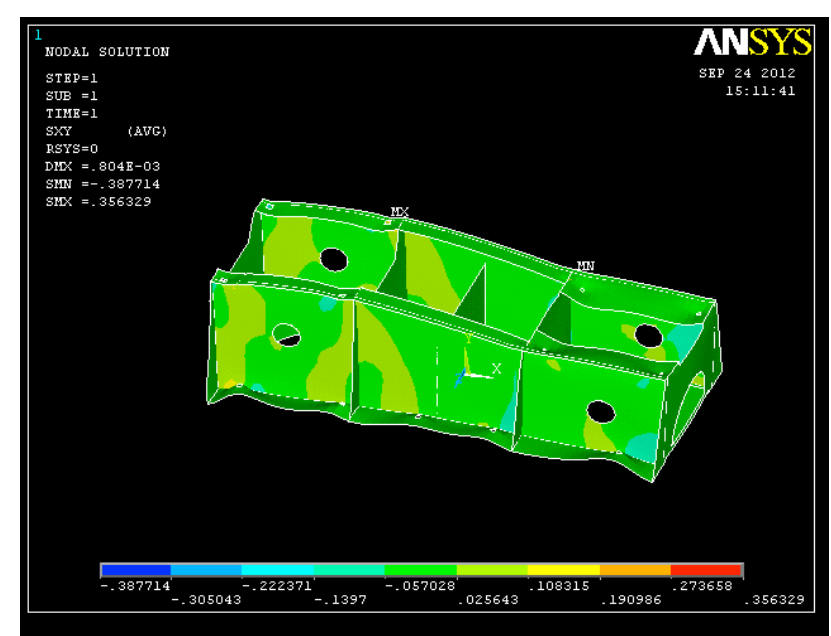

Fig. 8. Shear stresses in $X Y$ directions $\left(S_{x y}\right)$ of composite foundation

Eigen value analysis of nanocomposite:

To determine natural frequencies and mode shapes of nano composite foundation Eigen value analysis, here fifteen mode shapes were extracted. At $7^{\text {th }}$ node first natural frequency observed is $48.3 \mathrm{~Hz}$ and at the last mode i.e. 15th mode it is $613.50 \mathrm{~Hz}$. At $7^{\text {th }}$ mode the shape of the foundation is shown in the fig-9

The natural frequency at different modes of ' $\mathrm{CNT}$ reinforced with FRP composite'foundation in free-free modal analysis is tabulated in theTable-5.

Table 5. Free-free Eigen value analysis results of CNT Reinforced with CFRP foundation

\begin{tabular}{c|c}
\hline SET & FREQUENCY HZ \\
\hline 7 & 43.299 \\
\hline 8 & 219.90 \\
\hline 9 & 224.99 \\
\hline 10 & 236.61 \\
\hline 11 & 246.45 \\
\hline 12 & 257.19 \\
\hline 13 & 314.76 \\
\hline 14 & 324.48 \\
\hline 15 & 334.83 \\
\hline
\end{tabular}

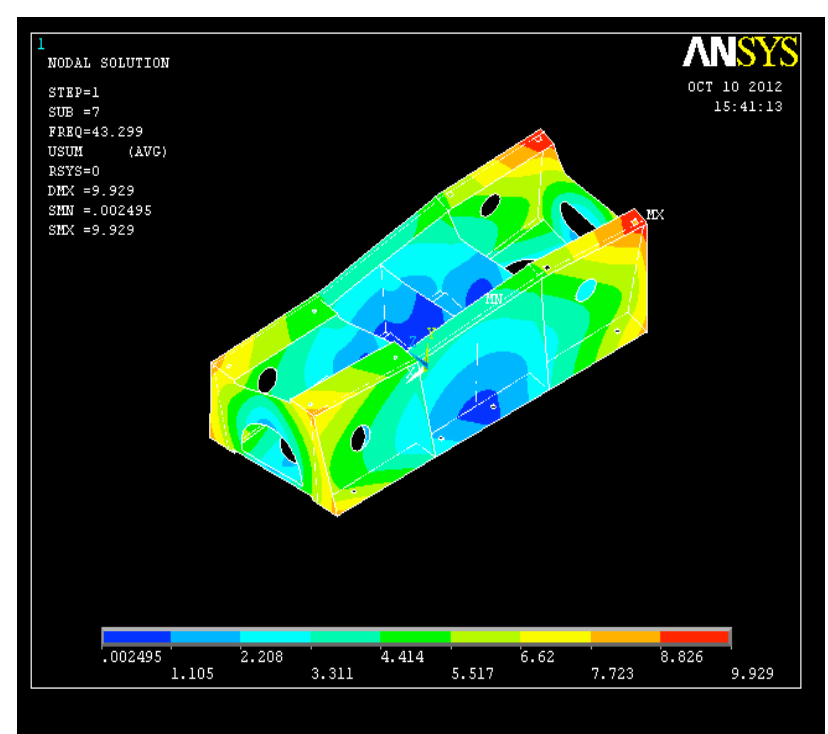

Fig. 9. 7th mode shape of CNT reinforced with CFRP foundation (FreeFree Eigen value analysis

In fixed boundary condition, the first natural frequency is observed at mode 1 as $219.05 \mathrm{HZ}$ and at last mode i.e. 15 th mode it is $464.59 \mathrm{HZ}$. Natural frequency at every mode is shown in the table-6

Table 6. Eigen value analysis results of CNT Reinforced with CFRP foundation (Constrained condition)

\begin{tabular}{c|c}
\hline SET & FREQUENCY HZ \\
\hline 1 & 219.05 \\
\hline 2 & 224.37 \\
\hline 3 & 244.36 \\
\hline 4 & 254.54 \\
\hline 5 & 260.36 \\
\hline 6 & 317.18 \\
\hline 7 & 338.65 \\
\hline 8 & 344.59 \\
\hline 9 & 354.20 \\
\hline 10 & 375.37 \\
\hline 11 & 402.19 \\
\hline 12 & 419.59 \\
\hline 13 & 439.09 \\
\hline 14 & 448.80 \\
\hline 15 & 464.25 \\
\hline
\end{tabular}

\section{Conclusions}

For the foundation of marine machinery, the CNT reinforced with CFRP composite material is well suitable compared to the traditional mild steel because of the following reasons.

Weight is reduced up to $40 \%$ which enables higher cruising speed, acceleration, maneuverability, and fuel efficiency.

The natural frequencies are reduced by $35 \%-45 \%$

Vibrations are reduced from mild steel to CNT reinforced with CFRP foundation.

This is an Open Access article distributed under the terms of the Creative Commons Attribution Licence

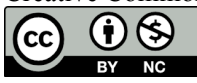




\section{References}

1. A. Shooshtari, M. Rafiee, 2011, Vibration characteristics of nanocomposite plates under thermal conditions including nonlinear effects. International Journal of Applied Research in Mechanical Engineering, Volume-1, Issue-1,

2. B. Ramgopal Reddy, K. Ramji, B.satyannarayana, 2011, Free vibration analysis of carbon nanotubes reinforced laminated composite panels world academy of science, Engineering and technology, 2011

3. Behnam, Ashrafi, 2008, Therotical and experimental investigation of the elastic properties of carbon nanotubes- reinforced polmer thin films, Ph.D thesis submitted at Mc Gill University.

4. C.M. Manjunatha,A.C.Taylor, A.J.Kinloch, S.Sprenger 2009 The tensile fatigue behavior of a silica nanoparticle-modified glass fibre reinforced epoxy composite, ELSIVER (Science Direct)

5. Ching-Chie Lin, Ya-jung lee, Chu-Sung Hung, 2008, Optimization and experiment of Composite marine propellers, ELSIVER (Science Direct)

6. Guru raja M.N, A.N Hari Rao,2012, A Review on Recent Applications and Future Prospectus of Hybrid Composites, International Journal of Soft Computing and Engineering (IJSCE) ISSN: 2231-2307, Volume-1,

7. Horacio, V. Duarte, L.azaro, V. Donadon, F. Avila Mechanical Properties of Nanocomposite Laminated Structures by Modal Method, 2nd International Conference on Engineering Optimization September 6-9, 2010, Lisbon, Portugal

8. Kaplevatsky I.D. and Raevsky V.G, 1977, "Stress-Strain State of Multilayer Composite Laminates", Composite Materials, Vol. 11. p. 445
9. Maksim Kireitseu, David Hui Advanced shock-resistant and vibration damping of nanoparticle-reinforcedcomposite material, ELSIVER (Science Direct)

10. Moreno Endo, Michaels Potential Applications of Carbon Nanotubes, Springer-Verlag Berlin Heidelberg 2008

11. Mouritz A.P., Gellert E., Burchill P. and Challis K., 2001, "Review of composite structures for naval ships and submarines", Composite structures, Vol. 53, pp. 21-41.

12. R. Rikards, A. Chate, E. Barkanov Finite element analysis of damping the vibrations of Laminated composites, ELSIVER (Science Direct)

13. R.V. Kurahatti, A.O.Surendranathan, S.A. Kori, 2010 Defence Applications of Polymer Nanocomposites, Defence Science Journal, Vol No. 60,

14. Shafi-Ullah Khan, Kosar Iqbal Quasi -static and impact fracture behavior of CFRPs with Nanoclay -filled epoxy matrix, National Engineering and Scientific commission, Islamabad.

15. Sujesh.G and C.Ganesan, 2012, Tensile Behavior of Nano Filled GFRP at Different Strain Rates, International conference on mechanical materials and automotive engineering

16. Taylor, T.W. and Nayfeh, A.H. (1994) 'Natural frequencies of thick, layered composite plates', Composites Engineering, Vol. 10, pp.1011-1021.

17. Yankelevsky David Z., 1991, "Analysis of a composite layered elastic foundation”, Int. J. Mech Sci., Vol. 33, No. 3, pp. 169-177 